\title{
Raça, gênero, classe, igualdade e justiça: representações simbólicas e ideológicas do filme Crash, de Paul Haggis
}

\author{
Eliezer Gomes da Silva \\ Doutor em Direito (Universidade de São Paulo) \\ Promotor de Justiça no Estado do Paraná \\ Professor das Faculdades Integradas do Brasil (Unibrasil) \\ Curitiba, Brasil \\ eligosil@terra.com.br \\ Eliane Borges da Silva \\ Doutoranda em Ciência da Informação (Universidade Federal Fluminense) \\ Chefe de Gabinete da Fundação Cultural Palmares, Ministério da Cultura \\ Brasília, Brasil \\ Eliane.borges@palmares.gov.br
}

Resumo

Este ensaio examina o filme $\mathrm{C}$ rash, de Paul $\mathrm{H}$ aggis, sob a ótica dos estudos sobre as relações raciais. Empreende uma leitura do conteúdo simbólico e ideológico da metalinguagem de $\mathrm{C}$ rash (a forma como a história é contada) e não da linguagem assumidamente racista de seus personagens (o conteúdo explícito da história contada). Cotejando, com fidelidade, a moldura ficcional e discursiva do filme com os horizontes analíticos históricos e contem porâneos no que tange ao tema das relações raciais (e suas correlações com questões de gênero, classe, igualdade e justiça), o ensaio identifica o modo como $\mathrm{C}$ rash se permite incorporar uma sub-reptícia ideologia racista (particularmente no estereotipado e estigmatizante delineamento moral dos personagens negros, comparativamente aos personagens brancos), sob o manto protetivo de um filme que aparentemente se propõe a combater o racismo. C rash seria, no argumento do ensaio, um típico exemplo - de ficção e de realidade - do que denomina por "antirracismo racista". Ao final, o ensaio chama a atenção para a responsabilidade social e ética da indústria do entretenimento e sua compatibilidade com a liberdade de criação artística.

Palavras-chave: racismo; antirracismo; gênero; classe; indústria de entretenimento.

\section{O enredo, sua trama e seus aparentes propósitos - uma síntese introdutória de Crash}

0 célebre filme $C$ rash tem uma trajetória de sucesso. Indicado a seis estatuetas do 0 scar em 2006, arrebatou três: melhor filme, melhor roteiro original e melhor edição. C onfirmação do talento de seu diretor e roteirista, Paul $\mathrm{H}$ aggis, que no ano anterior já havia sido indicado à premiação pelo roteiro de $M$ enina de ouro (M illion dollar baby), C rash é, sem dúvida alguma, um daqueles filmes que nunca se confrontará com a indiferença do espectador. Imprevisível (e portanto contraintuitivo), dramático (e portanto catártico), reflexivo (e portanto cerebrino), politicamente engajado (e portanto controvertido), propõe-se a narrar histórias de vida de personagens da cidade de Los A ngeles, que eventual- 
mente se esbarram (e não si mplesmente se encontram) quando trilham a senda comum do preconceito, do racismo, da discriminação.

Por meio de uma elaborada construção de personagens "redondos", de perfil psicológico complexo, com vacilante ou contraditório senso moral, o extraordinário roteiro, emoldurado por impecável fotografia e sedutora trilha sonora, desenvolve-se com competência em seu nítido desiderato: fugindo de uma ética maniqueísta ou politicamente correta, procura demonstrar que o racismo, o preconceito (e por consequência a discriminação) impregnam a nossa existência, quer disso estejamos cientes ou não. E isso é alcançado por múltiplos núcleos dramáticos.

De um lado, vemos os explícitos arroubos racistas do veterano policial Ryan (M att Dillon). Inicialmente (e com a contrariedade de seu parceiro, 0 jovem policial $\mathrm{H}$ ansen, interpretado por $\mathrm{R}$ yan Philippe), R yan será o responsável por uma revista policial sexualmente abusiva e humilhante em Christine (T handie $\mathrm{N}$ ew ton), na presença de seu marido $\mathrm{C}$ ameron (Terrence H oward), um bem-sucedido diretor de TV negro, quando tem seu carro parado. $M$ ais tarde, - mesmo R yan protagonizará insultos raciais contra Shaniqua Johnson (Loretta Devine), inconformado com o fato de o plano de saúde preferir um superficial e inócuo tratamento ambulatorial à doença de seu pai (como se fosse uma simples infecção na bexiga) a examinar a concreta possibilidade de tratar- se de câncer na próstata. Isso (no entendimento de R yan) a despeito de seu pai ter sido levado à ruína após a prefeitura passar a adotar políticas afirmativas, privilegiando a contratação de serviços geridos por afrodescendentes.

De outro lado, a esposa de um promotor público, Jean C abot (Sandra Bullock), após ter sido vítima de um roubo a um veículo da família, roubo este perpetrado por dois jovens negros, A nthony (interpretado pelo rapper Ludacris) e Peter Waters (interpretado por Larenz Tate), não mais dissimula 0 asco, a repugnância, o desconforto de conviver com o que lhe parece uma perigosa subclasse de bandidos negros ou de empregados latinos. Do arrependimento por não ter seguido seus instintos de que dois jovens negros são sempre suspeitos em potencial, segue-se a sua impaciência com a própria empregada doméstica, $M$ aria (Yomi Perry), que mantém a louça limpa na máquina de lavar (e não nos armários da cozinha), e a suspeição sobre o chaveiro Daniel (M ichael Peña), de quem (pelas calças de cós baixo, pelas tatuagens e pela cabeça raspada) desconfia que será partícipe de uma futura ação furtiva a sua residência, repassando a terceiros as chaves da fechadura que acaba de trocar.

0 preconceito e a discriminação de Jean não têm a aprovação de seu marido R ick (Brandon Fraser), promotor público. Contando com o suporte eleitoral da comunidade negra, esforça-se em suas manifestações públicas e atitudes profissionais para não trair a "confiança de seu eleitorado". C om efeito, da manipulação política da questão racial, pelo promotor $\mathrm{R}$ ick, que lamenta ter tido a infelicidade de ser assaltado por dois jovens negros, diante da inconveniente exposição na mídia do caso (o que, na sua avaliação, pode Ihe custar votos tanto da comunidade negra quanto dos adeptos da "lei e ordem"), segue- se a manipulação jurídica de um outro caso de possível conotação racial. Seu assistente Flanagan (W illiam Fichtner) é encarregado por $\mathrm{R}$ ick de um "servicinho sujo": convencer um detetive negro, G raham (D on C headle), a ajudar a encobrir as evidências vitimológicas adversas que envolvem 0 assassinato de um outro policial negro, Lewis. É que trezentos mil dólares foram encontrados no estepe do veículo que Lew is conduzia, embora o veículo não Ihe pertencesse. Tudo para não atrapalhar um caso exemplar de punição do assassino de um jovem negro (Lew is) por um policial branco, Conklin ( $\mathrm{M}$ artin N orseman), com histórico de outras duas mortes suspeitas de jovens negros, embora possivelmente Conklin tenha agido em legítima defesa, considerando o aparentemente ilícito comportamento de Lewis e sua contrariedade em ter o veículo vistoriado. De quebra, G raham seria promovido (aumentando a visibilidade dos negrosem cargos estratégicos de indicação da promotoria) e o irmão de Graham, Peter, duplamente reincidente em crimes patrimoniais, poderia ter suspenso o cumprimento do mandado de prisão (capaz de lhe custar uma prisão por tempo indeterminado).

Após inicialmente recusar, com veemência, a proposta de Flanagan, como condição para a sua promoção, G raham ouve o desabafo dele. Primeiro, sobre a aparentemente incontrolável inclinação dos negros em geral à criminalidade, contrariando as explicações sociológicas que registra ter conhecimento sobre a seletividade do sistema penal. Segundo, sobre a necessidade de serem criados ou preservados símbolos positivos para jovens negros (para Flanagan, é preferível confrontarem-se com Lew is como um mártir negro que como um traficante de drogas). Chamado à responsabilidade por isso, G raham dá sinais de consentir com 0 acobertamento das evidências contra Lewis, principalmente pelo apelo de ordem pessoal (evitar a prisão de seu irmão Peter).

N um outro núcleo da trama, Fahrad (Shaun Toub), antigo imigrante iraniano, naturalizado americano, apesar de seu inglês precário e errante, vê recusada a venda de uma arma. Sofre explícita discriminação pelo vendedor americano, que vê em Fahrad a imagem ea semel hança de um terrorista islâmico suici$\mathrm{da}$, nos moldes dos que se envolveram no 11 de setembro, recusando-Ihe até mesmo o "direito de possuir armas", que a segunda emenda à Constituição americana atribui a todos os seus cidadãos, direito invocado por Fahrad, mesmo reconhecendo não ter o mínimo preparo para o manuseio de armas de fogo (ou para a 
escolha da munição apropriada). C com a intervenção de sua filha, Dorri (Bahar Soomekh), que sutilmente invoca seus direitos de consumidora, a compra da arma e da munição é efetivada, após grande altercação. $M$ ais tarde Fahrad, que não seguira as recomendações do chaveiro $D$ aniel (de que deveria trocar a porta emperrada e não apenas a fechadura), tem sua mercearia furtada e vandalizada. Vendo recusado o pagamento da indenização do seguro por alegada negligência no conserto da porta, Fahrad volta sua fúria para $\mathrm{D}$ aniel. De posse da arma adquirida, persegue D aniel em sua residência, chegando, por erro de execução, a disparar contra a pequena fillha de Daniel, Lara (A shlyn Sanchez), que, contudo, não é atingida porque a munição adquirida (resultado, ao que tudo indica, da escolha aleatória de Dorri, na tumultuada venda - e para a tranquilidade do vendedor) era de festim.

Em meio a toda essa trama de incompreensões e intolerâncias, A nthony procura conscientizar seu parceiro de crime, Peter, sobre racismo e desigualdade de oportunidades em todos os aspectos da sociedade norte- americana (Peter vê exagero nas afirmações de A nthony). $M$ as as vidas de Peter e A nthony se entrecruzam num acidente, com o atropelamento do coreano Choi (G reg Joung Paik), marido de $\mathrm{K}$ im Lee (A lexis $R$ hee), que por sua vez troca insultos com $R$ ia (Jennifer Esposito), quando R ia e K im se envolvem num acidente de carro. O portunamente, recuperando-se do atropelamento no hospital, descobre-se que Choi está envolvido com o tráfico de pessoas do Camboja e da Tailândia, casualmente encontradas por A nthony acorrentadas no interior da enorme van que furtou.

$\mathrm{H}$ ansen, 0 jovem policial branco, confrontado com as atitudes abusivas de seu colega de ronda, $R$ yan (especial mente após a abordagem que este fez a $\mathrm{C}$ hristine e a $\mathrm{C}$ ameron), não hesita em pedir a seu superior hierárquico, o tenente negro Dixon (Keith David), para não mais acompanhá-lo em suas rondas, estando disposto, se necessário for, a formalizar denúncia contra $\mathrm{R}$ yan por racismo. 0 fato é minimizado pelo tenente Dixon, que expõe seu temor de que a apuração das práticas racistas, de R yan, um policial que há anos esteve sob sua supervisão direta, possa trazer prejuízos ao próprio Dixon, cuja ascensão na carreira policial Ihe teria custado muito, no ambiente racista da polícia de Los A ngeles, 0 que $D$ ixon pede a $H$ ansen que leve em consideração. N estes termos, D ixon apenas consente que o jovem idealista branco faça sozinho suas rondas (sugerindo- Ihe o motivo formal para tanto: flatulência incontrolável), sem adotar qualquer providência em relação a R yan.

$N$ esse vaivém de encontros e desencontros, de preconceitos, ódios, incompreensões, prevaricações, intolerâncias, oportunismose incompreensões mútuas (na verdade, as colisões, físicas, morais e metafóricas que o título do filme evoca), surge uma cena surpreendente. $\mathrm{O}$ jovem idealista $\mathrm{H}$ ansen, de folga, ao dar carona a Peter Waters, numa noite fria de inverno, é tolhido por seu próprio preconceito, ao atirar contra o carona, erroneamente supondo que Peter estava prestes a sacar uma arma, quando em verdade apenas detinha uma estatueta de São C ristóvão, do mesmo tipo que, por coincidência, viu no carro do policial $\mathrm{H}$ ansen e que gerara um gracejo de Peter, atiçando a irritação do policial, até então politicamente correto, e levando- 0 a ordenar a Peter que saísse do carro, após pedir (sem ser obedecido) que ele lhe mostrasse o que tinha em sua mão. M orre assim Peter, o irmão de Graham, a quem sua mãe (interpretada pela atriz B everly Todd), viciada em crack, pedia insistentemente que localizasse e trouxesse para casa. E o filme termina com uma batida entre o carro da gerente do plano de saúde, Shaniqua, e o veículo de um terceiro, de origem latina.

Evidentemente, essa apertada síntese amesquinha a força dramática do roteiro, muito bem construído e muito bem interpretado por um elenco de primeira linha (com perfeita distribuição de papéis), num filme que, grosso modo, não tem personagens principais. De qualquer forma, o que pretendíamos deixar assentado, como premissa fático-argumentativa para as considerações seguintes, as quais, doravante, tentarão justificar o título e o tema deste artigo, é que toda a história é construída em encontros aparentemente casuais de personagens, cujos discursos e atitudes, contraditórios e moralmente questionáveis, nos fariam antever ou lembrar que o preconceito, o racismo, a discriminação fazem parte de nossa experiência diuturna de vida, com o que deveríamos todos nos envergonhar, embora cientes da ausência de soluções simples para o seu enfrentamento. Esta, al iás, é a chamada " interpretação autêntica" exposta pelo próprio autor da história, Paul $\mathrm{H}$ aggis (bem como os autores envolvidos), nos depoimentos que presta nos "extras" do DVD: um filme forte, sincero, que se propõe a debater o preconceito (o "medo dos estranhos"), o racismo, de forma crua e brutal, com suas nuances mais complexas (em que se misturam questões de gênero e de classe), com 0 propósito de combatê-lo ou de ridicularizá-lo.

\section{Os "atos falhos" de Crash}

\subsection{O racismo de um filme antirracista}

Examinando-se mais detidamente o filme, com a licença que o caráter aberto de sua trama nos dá (e o viés convictamente racial de sua temática), chegamos, sem muito esforço, à constatação de que $C$ rash inserese naquele rol de trabal hos que, a pretexto de abordarem de forma direta a questão racial, com declarado objetivo ecumênico ou de pacificação social, acabam 
por prover ao racismo sutis conotações simbólicas de forma muito próxima de sua própria justificação. É que a atenta análise de cada cena, cada quadro, cada plano do filme bem revelará (não importa aqui se de forma deliberada ou não por seus criadores - e preferimos acreditar tratar-se de um "ato falho") que a lógica aleatória, da "mera coincidência", do "acaso", do "inesperado", na sequência de encontros e desencontros entre os personagens (marca cativante da narrativa, que tem despertado entusiasmados elogios de todos os que assistem ao filme), não é seguida, em momento algum, no delineamento moral dos personagens negros e brancos. A qui nada acontece de forma diversa do que poderia supor a ideologia racista. M uito pelo contrário: a trama é absolutamente coerente (do início ao fim) com o privilegiamento moral dos personagens brancos, em detrimento das minorias étnicas (especialmente os negros e, num grau menor, os orientais, sendo até condescendente com os personagens latinos). E essa representação simbólica, de inferiorização moral de um grupo de determinada origem étnica ou racial (aqui entendida como conceito socialmente construído), em detrimento de outro, não pode deixar de constituir a marca mais característica da ideologia racista - de ontem e de hoje -, permitindo-se uma leitura deste significado ideológico sub-reptício a $\mathrm{C}$ rash principalmente em sua metalinguagem (a forma racista como a história é contada) e não por seus óbvios referenciais à linguagem racista de seus personagens (a mensagem antirracista que a história quer passar) (R oso et ali., 2002, p. 80).

Certamente não terá sido "mera coincidência" a forma desnecessariamente racista com que os personagens negros são moral mente estruturados, ao serem inseridos numa cinematografia engajada na luta pelo racismo. C rash apresenta-se como de cunho antirracista, na medida em que delineia personagens vítimas de discriminação e preconceito, diretamente relacionados a sua etnia ou a sua nacionalidade, consideradas pelos ofensores como intelectual, social e moralmente inferiores. Entretanto, o filme também subscreve essa ideologia racista, quando deixa de atribuir a esses personagens (vítimas do racismo) qualidades morais, éticas ou intelectuais positivas, que não hesita em vincular aos personagens brancos do filme, a despeito das falhas morais que Ihes delineia, como se verá adiante. C omo que imbuído do propósito de deixar claro na trama ficcional que, talvez, em certos aspectos, as vítimas do preconceito, da discriminação, justifiquem, com seu comportamento e com suas atitudes, muitos dos fundamentos da ideologia racista. $R$ eedita-se aqui, com ferramentas contemporâneas, um sub-reptício e subliminar discurso de uma intrínseca superioridade moral, social e intelectual dos brancos, sob o perverso manto protetivo de um filme que aparentemente se propõe a combater o racismo (o que nos induz à legítima expectativa de que deixaria uma mensagem positiva de pacificação social) (Paiva; Sodré, 2004, p. 147).

Portanto, poderíamos identificar em C rash um "antirracismo racista", a que se opõe o "racismo antirracista", antológica expressão cunhada por Sartre em 1948 (Guimarães, 2005, p. 67). M as tais assertivas e conclusões hão de ser provadas e documentadas de modo suficientemente objetivo, com fundamentação especial mente rigorosa (porque contraintuitiva) e com fidelidade à moldura ficcional e discursiva (o que nos foi facilitado pela regularidade com que esse padrão ideológico-discursivo se faz presente no decorrer de todo 0 enredo de $C$ rash). É o que faremos a seguir.

\subsection{Focando e analisando alguns "atos falhos"}

I. É certo que quase todos os personagens do filme não são isentos de fal has ou defeitos morais, independentemente de raça, gênero, classe socioeconômica ou da posição que eventualmente ocupem no sistema jurídico-penal (os policiais, o promotor público ou seu assistente), pano de fundo para muitos dos dramas vivenciados pelos personagens. A exceção seriam os personagens "quadrados" de origem latina (Daniel, $M$ aria e $R$ ia) ou mesmo de origem árabe (como D orri, filha de Fahrad), os quais demonstram perfeita assimilação dos valores da sociedade branca norteamericana. 0 curioso é que aos personagens brancos norte-americanos se permite uma redenção moral de seus "pecados", uma até antiquada "justiça poética", o que é inexoravelmente negado a qualquer dos personagens negros de $\mathrm{C}$ rash. M uito ao contrário, estes parecem sempre retratados como irremediavel mente responsáveis por suas próprias desgraças. Vejamos:

II. O policial branco, ostensivamente racista, Ryan, que realiza uma revista sexualmente abusiva na esposa (Christine) do jovem diretor de TV negro $C$ ameron, na presença deste, redime-se com a atitude heroica (e duplamente humilhante para a própria C hristine e para ( ameron) de salvar a vida de C hristine, resgatando-a de um carro acidentado, pouco antes de explodir. Nítida a mensagem moral: ainda que R yan tenha lá seus desvios de conduta, é um policial destemido, corajoso, a quem Christine deverá ser eternamente grata, porque Ihe salvou a vida, perdoando-o pela "indelicadeza" da revista abusiva. ${ }^{1}$ A cena de R yan abraçado a C hristine, quando salva sua vida, e que ilustra o material promocional do DVD, é bem característica dessa mensagem corrente do filme,

1 Imbuído de surpreendente e inoportuna gentileza (ambos estão no interior de um veículo capotado, prestes a explodir), Ryan chega a abaixar o vestido de Christine, durante o salvamento, pedindo-lhe a todo o momento licença para tocá-la. Salva por Ryan, Christine o abraça, agradecida, protegida, ainda que constrangida. 
a despeito de seu propósito de denunciar o racismo: 0 que seria dos negros não fossem os brancos?

III. Esse mesmo policial R yan, que não se contém em insultar, com termos explicitamente racistas, por duas vezes (por telefone e pessoal mente), a gerente negra do plano de saúde, Shaniqua Johnson, redime-se com a preocupação que demonstra ter pelo sofrimento a que injustamente seu pai é submetido, sem a adequada assistência médica, pelo modesto plano de saúde que tem condições de pagar, após anos de trabalho árduo. $\mathrm{N}$ ão bastasse isso, as palavras proféticas desse veterano policial ao colega mais jovem e idealista, $\mathrm{H}$ ansen ("Espere até que você esteja por mais alguns anos nesse trabalho"), são confirmadas pelas próprias circunstâncias em que $\mathrm{H}$ ansen acaba matando o jovem Peter. Q uase que a corroborar o maior dos mitos da chamada cop culture: de que a dureza das ruas, a maior exposição ao submundo da criminalidade (preço que pagariam os que se propõem a garantir a paz e a segurança pública - mais que um trabalho, uma "missão"), traz inevitavelmente "incidentes", "acidentes de trabalho", por melhores que sejam as intenções de muitos dos que ingressam nos quadros policiais (cf. R einer, 1992). O u seja, o policial $R$ yan é um homem experiente, honesto, dedicado a seu trabalho, ainda que um tanto "tosco", "rude", atributo inevitável aos que trabal ham "nas ruas".

IV. A inda que a longa cena não deixe dúvidas em retratar a prática de uma revista policial sexualmente abusiva por $\mathrm{R}$ yan a C hristine, o carro de luxo do bem-sucedido diretor de TV negro é parado por $\mathrm{R}$ yan (mesmo após $\mathrm{H}$ ansen observar que não é a mesma placa do carro roubado que procuravam) porque o casal (C hristine e $C$ ameron), animado no retorno de uma cerimônia de premiação, praticava sexo oral com 0 veículo em movimento. A ssim, 0 inaceitável abuso de R yan, a Christine e a $\mathrm{C}$ ameron, acaba sendo contraposto ao fato de que, tivesse 0 casal negro se comportado de forma mais decente, mais civilizada, contendo-se de seus desejos sexuais, e não fosse Christine tão desbocada, o desfecho da abordagem, por $\mathrm{R}$ yan, talvez fosse outro. A consciência, por $\mathrm{Ca}$ meron, de que seu comportamento no veículo (ao permitir-se a fellatio de Christine) era socialmente inaceitável, deixa- o "nas mãos do policial R yan". A té para evitar o escândalo (sobre as razões da detenção) que eventual reclamação aos órgãos correcionais da polícia lhe acarretariam. C omo diz C hristine: não reage $\mathrm{C}$ ameron à atitude abusiva de $\mathrm{R}$ yan, sequer denunciando-0, para que seus amigos não se lembrem de que ele [C ameron] nunca passou de um negro, de quem não se poderia mesmo esperar se comportasse de forma diversa. $\mathrm{O} u$ (como diria $\mathrm{R}$ yan ou Flanagan): não se comportassem os negros de forma tão desviante das regras da sociedade civilizada (o que tornaria um mito a discriminação racial na construção dos "suspeitos", durante as abordagens policiais), ${ }^{2}$ boa parte de seus problemas com a polícia e a justiça não existiria. $R$ eedita-se aqui a crença no duro "fardo civilizatório do homem branco", de que nos fala Ianni (2004, p. 22). U ma vez mais a mensagem: a vida dos brancos seria menos custosa não fossem os negros.

V. Contudo, isso não basta ao aniquilamento moral de Cameron. 0 olhar lascivo do policial sobre Christine (e provocativo de C hristine sobre R yan, antes de sair do carro), entremeada a impropérios verbais de uma descontrolada $C$ hristine, seguida da revista sexualmente abusiva, por $\mathrm{R}$ yan, retira do jovem negro (já privado do respeito que normal mente sua condição socioeconômica "superior" Ihe proporcionaria - não basta ter dinheiro, é preciso ser branco) sua própria masculinidade. $\mathrm{H}$ á uma castração simbólica de $\mathrm{Ca}$ meron, em alguns aspectos tão impactante quanto um profundo ato de racismo, embora dele derivado, a mesclar dimensões de gênero e raça. C ameron é humilhado como homem porque incapaz de proteger sua fêmea dos abusos de outro macho. E não bastasse o estupro simbólico de sua mulher (o estupro, como arma de guerra, constitui imagem corrente ao longo da história, muito menos pela satisfação sexual que proporciona, e muito mais pela castração simbólica do derrotado, a marcar sua patente inferioridade) (D iken, Lautsen, 2006; M ilillo, 2006) é ainda humilhado por Christine, que não se conforma com o fato de ele não ter reagido ("O que eu preciso é de um marido que não fique parado enquanto eu sou molestada"), embora mais tarde ela procure entender as razões de Cameron (ainda que nunca se conforme). A qui mais uma ironia sobre o politicamente incorreto: C hristine consente que o marido "fez a coisa certa" (o que era menos lesivo ao corpo e à imagem de ambos na situação), mas ainda assim se ressente de sua falta de virilidade, de sua dignidade de macho ser subtraída, masculinidade que vai mais tarde encontrar na figura destemida e protetiva do policial branco e racista que, mesmo pondo em perigo a sua própria vida, a salva da morte. Virilidade, coragem, ousadia, utilizados por R yan com inteligência e no momento próprio, e não de forma inoportuna, como a estúpida investida de Cameron aos policiais, quando assaltado por Peter e Anthony.

Ao homem negro fraco, incapaz de salvar a esposa do abuso ou do perigo, sem poder denunciar aos órgãos competentes o comportamento abusivo de $\mathrm{R}$ yan (porque tudo teria derivado do comportamento sexualmente promíscuo de Cameron e Christine), contrapõe- se a superioridade masculina de $\mathrm{R}$ yan, que não apenas abusa sexualmente de C hristine, na frente de seu esposo, mas é corajoso o suficiente para colocar em perigo sua própria vida para salvá-la de um aci- 
dente de carro. R yan é a imagem perfeita do macho, que C hristine (reforçando os estereótipos de gênero) com a ajuda da surpreendente cena do salvamento - a contragosto gostaria de ver em $\mathrm{C}$ ameron.

VI. H ansen, o jovem policial branco, reconhecendo $\mathrm{C}$ ameron pela humilhação que $\mathrm{R}$ yan 0 submetera, intercede numa outra abordagem policial ao diretor de TV, que também tem a vida salva por um policial branco. É que $\mathrm{C}$ ameron, de modo absolutamente irracional, suicida mesmo, não apenas reage a uma tentativa de roubo a seu veículo (perpetrado por A nthony e Peter), mas, tendo arrebatado a arma dos ladrões, ao invés de exigir sua prisão, passa a desafiar os próprios policiais que surgem (como se estivesse a roubar o próprio carro), pedindo-Ihes que se ajoel hassem e Ihe praticassem sexo oral, prometendo gestos ainda mais ameaçadores. $\mathrm{N}$ ão fosse pela casual intervenção de $\mathrm{H}$ ansen, $\mathrm{C}$ ameron certamente seria morto em "legítima defesa" (como se apressa em esclarecer 0 jovem policial $\mathrm{H}$ ansen). Pobre $\mathrm{C}$ ameron: mal sabe escolher a ocasião e os meios mais racionais para uma atitude heroica, para expressar sua indignação contra uma sociedade racista, sexista, segregacionista. 0 que seria de $\mathrm{C}$ ameron, se não fosse $\mathrm{H}$ ansen? $\mathrm{O} \mathrm{u}$, uma vez mais: o que seria dos negros ("naturalmente" irascíveis, temperamentais, impulsivos, inconsequentes, irracionais, como Cameron), se não existissem brancos como $\mathrm{H}$ ansen (que salva a vida de $\mathrm{C}$ ameron) ou mesmo $R$ yan (que salva a vida de $C$ hristine)?

VII. O mesmo C ameron, embora diretor de TV, se deixa convencer, pela sugestão de seu assistente branco, a refilmar uma cena tecnicamente perfeita, simplesmente porque o personagem negro ousara utilizar uma frase que traduziria uma expressão "incompatível" com o caráter tosco que um negro presumivelmente estaria fadado a representar (estereotipada, gramaticalmente inadequada, segundo os registros da norma culta). Vale dizer, C ameron nem mesmo é capaz de exercer seu legítimo e incontrastável poder como diretor de uma cena no exercício de sua profissão, pois de quem nasceu para ser escravo não se pode esperar que aja como "senhor" (a dialética "senhorescravo", de que nos fala Ianni, não poderia estar aqui melhor simbolizada) (Ianni, 2004, p.27). A o contrário de R yan, o policial branco que luta por suas convicções e que, a seu modo, mantém o controle de tudo e de todos.

VIII. Em suma, por ser negro, C ameron não é macho (porque incapaz de defender - ou satisfazer sua própria fêmea) e nem é rico (apesar de ser um homem de posses, não é respeitado como tal e sua posição econômica não Ihe permite, por razões próprias e externas relacionadas a sua raça, fazer valer seus direitos). $\mathrm{N}$ ão sabe se comportar de forma adequada, decente em público, ao volante de seu carro, nem se impor perante as insinuações estereotipadas (e racistas) de seu assistente de direção. 0 u seja, nem comandar sabe. 0 atributo racial priva Cameron, a um só tempo, do ser e do ter, por um ato abusivo de um agente do Estado, e com o reforço dos estereótipos de gênero que sua mulher parece mais inclinada a observar. $M$ ais que isso: a tolerância, a resignação de $\mathrm{C}$ ameron, os modos de adaptação que aprendeu a realizar para seguir seu rumo numa sociedade racista, conquanto Ihe assegurem relativo sucesso profissional, privam-no de sua dignidade humana (como Ihe bradou Christine), na medida em que representam rituais típicos da dialética "senhor-escravo". Equilibrando-se de forma utilitária nessa corda bamba, entre os valores do individualismo e do racismo, que o leva a dobrar-se diante de R yan e de seu assistente, C ameron não consegue ser negro nem consegue ser branco. $N$ ão consegue ser pobre nem consegue ser rico. E só essa constituição moral amorfa, ambígua e contraditória, aniquiladora de sua individualidade, poderia explicar a postura suicida que adota, no episódio da tentativa de roubo de seu veículo.

IX. O s insultos racistas de R yan a Shaniqua Johnson, porque presumivelmente justificáveis pelos arroubos irracionais de um filho diante do drama vital do pai, circunscrito às amarras de um sistema de saúde injusto, são obnubilados de forma muito mais contundente do que a nítida confissão, por Shaniqua, de que a solução para o pai de R yan poderia ser encaminhada com maior "boa vontade" caso o próprio pai (e não 0 arrogante $R$ yan) tivesse comparecido (o que não quer dizer que Shaniqua tenha solicitado sua presença). N esse sentido, não deixa de ter razão R yan, ao observar que a Shaniqua bastaria tão-somente um "rabisco de sua caneta". Temos então uma gerente negra de um plano de saúde que, por conta dos insultos de R yan (pelo contexto do filme " justificáveis" diante do drama do pai, vivenciado pelo filho, e pelo "sacrifício" que o paciente sofreu em sua vida pessoal com a implantação de políticas de ação afirmativa), prejudica um terceiro inocente, o idoso e moribundo pai de seu ofensor. A mensagem, uma vez mais, é clara: essas negras são mesmo vingativas, impiedosas, insensíveis, arrogantes e ingratas. Sequer se sensibilizam com a dor sofrida por um idoso doente, "mártir" das políticas de ação afirmativa. N ão por acaso, a mesma Shaniqua, na cena final, logo após se envolver num pequeno acidente de carro, dirige-se ao motorista do carro de trás exigindo-Ihe que fale o idioma "americano" (e não a língua inglesa), encerrando-se o filme com mais essa alegoria, da boca de um personagem negro, ao preconceito, à discriminação, à ignorância. $M$ ais uma vez, enquanto $R$ yan, ao longo do filme, redime-se de suas fal has de caráter (de abusador a injustiçado), 0 espectador assiste (sem redenção alguma) ao rebaixamento moral de Shaniqua.

$X$. Contrastemos agora a família de R yan com a família Waters. Enquanto o pai do policial Ryan, cidadão de bem e trabalhador, conseguiu-Ihe forjar 0 
gosto pelo trabal ho lícito (ainda que sujeito a inevitáveis "acidentes de percurso" ) e sua preocupação com o bem-estar de seus familiares, a mãe de Graham e Peter, que permanece inativa em sua casa apenas consumindo crack, duplamente fal ha em seu "legado" moral aos filhos. Por um lado, há de ter fal hado (esta a mensagem do filme) na formação moral de Peter, que, ao invés de se dedicar ao trabalho lícito, torna-se um ladrão de automóveis. Por outro lado, embora tenha conseguido incutir em Graham a inclinação para o trabal ho honesto, não se houve bem em fazer com que ele nutrisse um senso de solidariedade familiar (a cena em que Graham encontra comida estragada na geladeira da casa da mãe é bem sintomática de seu abandono) ou mesmo o mínimo senso de respeito familiar, de educação, de civilidade. É preciso que a namorada de Graham, R ia (Jennifer Esposito), branca - ainda que de ascendência latina - , o repreenda moralmente por ter interrompido a ligação que sua mãe Ihe fazia para Ihe declarar que não podia atendê-la porque estava "fazendo amor com uma mulher branca", de cuja nacionalidade nem mesmo está certo (a tem por mexicana, quando na realidade é fil lha de pais salvadorenhos e porto-riquenhos, o que Ihe vale uma aula de geografia por parte de $\mathrm{R}$ ia). M ais uma vez o estereótipo racista: os negros são mesmo uns mal-educados, grosseiros, comportam-se de forma menos civilizada que os brancos, dão mais importância ao sexo que a qualquer outra coisa. No entanto, isso é de somenos importância em relação a G raham: mais significativa é sua paulatina degradação moral, ao preferir participar de uma fraude para livrar o irmão de uma prisão que atender aos insistentes pedidos de sua mãe para que procurasse 0 irmão caçula e o trouxesse para casa, 0 que poderia contribuir para a recuperação do irmão caçula, sendo por isso acusado por ela de ser responsável pela morte de Peter.

XI. A morte do jovem Peter, embora decorrente de uma falsa representação da realidade pelo policial $\mathrm{H}$ ansen (que toma uma estatueta de São C ristóvão como se fosse uma arma), é antecedida de uma atitude inconsequente de Peter, que seguidas vezes ignora 0 apelo de $\mathrm{H}$ ansen para mostrar 0 que tem em suas mãos. C omo se estivesse "pedindo para morrer", numa espécie de "legítima defesa putativa" (erro de tipo permissivo), na expressão técnica dos penalistas. Embora a aparente moral da história seja a de que até 0 insuspeito $\mathrm{H}$ ansen guardava um resquício de preconceito (que levou a seu equívoco), toda a cena é elaborada de modo que também $\mathrm{H}$ ansen possa se redimir dessa sua falha trágica, pois tudo indicava que Peter o induziu ao engano. M ais uma vez, os negros são os responsáveis por seu próprio infortúnio. M ais uma vez um embaraço causado a um branco por uma atitude inadequada de um negro. A mensagem é clara: maldito dia em que $\mathrm{H}$ ansen (contrariando a postura corrente numa comunidade racista) resolveu dar carona a um jovem negro. A vida de policiais brancos como $H$ ansen seria muito mais fácil se não existissem negros inconsequentes como Peter. $\mathrm{H}$ ansen certamente se arrependeu da "politicamente correta" carona dada a um negro, numa noite fria de inverno, assim como Jean Cabot maldisse 0 instante em que, mesmo intuindo que seria assaltada por dois jovens negros, não mudou de direção.

XII. Flanagan, assistente do promotor R ick, enuncia seu brado contra as políticas de ações afirmativas, com 0 argumento de que, independentemente das inegáveis constatações de seletividade racial do sistema penal, os negros parecem compulsivamente, atavicamente (diria um darw inista social), inclinados a "colocar a mão no jarro", o que, segundo a teoria de Flanagan, justificaria o fato de que os dois irmãos (Peter e G raham), mesmo com oportunidades equivalentes, tenham tido destinos completamente díspares. $\mathrm{N}$ esse aspecto, Flanagan (e o promotor $\mathrm{R}$ ick, que representa) incorpora o que al guns analistas chamam de "racismo ambivalante" (Lima, Vala, 2004, p. 406).

$\mathrm{N}$ essa mesma cena número 8 de $\mathrm{C}$ rash, Flanagan, ao terminar de expor osfundamentos de sua tese de que "no fundo, nenhum negro é flor que se cheire", ainda se oferece, com a generosidade branca, para adotar uma política afirmativa tão radical que é baseada na injustiça: pede a colaboração do detetive negro Graham para que a promotoria acuse de homicídio com conotações raciais um policial branco potencialmente inocente, Conklin, encobrindo as evidências de que a vítima (irmão "de cor" de Graham) não era inocente. Com a simultânea promessa de promover Graham para uma posição de destaque e abstendo-se de dar efetividade à prisão, por tempo indeterminado, do irmão "de sangue", Peter. Tudo isso para que o sistema judicial (sob os auspícios do promotor e de seu assistente) sinalizasse estar política e juridicamente comprometido com as minorias raciais ou étnicas dos EU A.

Poucas vezes nos deparamos com eixo argumentativo e ideológico (ainda que ficcional) tão cruel e cínico como pano de fundo para uma crítica às ações afirmativas. A proposta indecorosa de Flanagan (de em nome da "causa negra" realizar-se uma injustiça) parece significar um alerta velado, sub-reptício, dos perigos, dos riscos a que podemos estar submetidos, caso levemos às últimas consequências as medidas compensatórias das desigualdades raciais. $\mathrm{O}$ u (o que é mais grave) como as concessões às reivindicações de justiça, baseadas na diversidade, seriam no fundo incompatíveis com os princípios de justiça que nortearam a civilização europeia e que, posteriormente, foram transplantados para suas colônias. Como se os reclamos de inclusão social, política e jurídica das minorias raciais e políticas corrompessem o equilíbrio perfeito da civilização branca de matriz europeia. Subverte-se aqui a crítica normal mente feita à "lógica da identidade" (H udson, 2007, p. 13). 
XIII. Embora se possa afirmar que a solução "particular" aventada por Flanagan (e, por via oblíqua, por R ick, na esfera pública), sendo moralmente insustentável, não poderia ser adicionada à conta das supostas "redenções" morais dos personagens brancos, não podemos esquecer que o rebaixamento moral do policial negro, Graham, que acaba aquiescendo com a proposta de Flanagan, há de ter relevância dramática muito mais proeminente (posto que vinculado a um personagem com senso ético até então inabalável) que as ilações de quem desde o início se apresenta como o responsável pelo "servicinho sujo" de uma instituição do Estado (a promotoria). Aqui mais uma perversa mensagem do chamado "antirracismo racista" incorporada na construção de C rash: os próprios negros são os corruptores do sistema, na medida em que, contrariamente às "evidências" de sua natural "inadaptação social" às regras do mundo civilizado, al heios às perspectivas do A merican dream, ainda forçam a maioria branca, em nome da pacificação social, vez por outra Ihes dar eloquentes razões de que o sistema oficial reconhece que vivemos numa sociedade injusta e desigual e de que se esforça para melhorar (nem que seja construindo um mártir negro e injustiçando um branco). A velha lógica racista, subjacente ao cínico discurso antirracista de Flanagan: embora tudo fosse mais fácil se o detetive Lew is não traficasse, ou se Peter, irmão do detetive G raham, não praticasse seguidos furtos e roubos, uma vez que o tema da desigualdade racial adquiriu tamanho peso político, é inevitável que os brancos aproveitem as ocasiões politicamente propícias para uma (falsa) demonstração de sensibilidade para com as minorias raciais ou étnicas. $\mathrm{N}$ egar o racismo não parece ser mais uma estratégia válida. M elhor reconhecê-lo enfaticamente, vez por outra, no plano oficial, na esfera pública (ações de governo, declarações à imprensa - como as empreendidas por Flanagan e R icky), e continuarmos a subscrever, no íntimo, na ordem privada, os fundamentos da ideologia racista.

XIV. N enhum atributo moral positivo é tampouco vinculado a Dixon, o tenente negro que se recusa a encaminhar uma acusação formal de racismo contra $\mathrm{R}$ yan (que $\mathrm{H}$ ansen, policial branco, estava disposto a deduzir), sob o improvável receio de que $D$ ixon poderia ser acusado de não ter se apercebido antes do comportamento racista de $\mathrm{R}$ yan, quando este estava sob sua supervisão, o que poderia prejudicar sua carreira. Como se fosse natural ou plausível que um policial branco e racista explicitasse seu preconceito, realizasse seus atos discriminatórios para que seu superior negro pudesse testemunhá-los. Essa pífia justificativa para a recusa de Dixon em encaminhar a reclamação de $H$ ansen é um argumento forçado para a nova mensagem decorrente do rebaixamento moral de outro personagem negro: esses negros, mesmo quando em posição de comando, são egoístas e prevaricadores, ainda que esteja em jogo a luta pela superação do racismo.

$X V$. A té mesmo Jean Cabot (Sandra Bullock), que abertamente expõe a seu marido $R$ ick suas suspeitas em relação ao chaveiro $D$ aniel (na presença do próprio $D$ aniel, que ainda se encontrava na residência) e assume seu preconceito em relação à "inclinação" dos negros à criminalidade (na presença da assistente negra do promotor $\mathrm{R}$ ick), também tem a oportunidade de se redimir de seu preconceito contra os "outros" (negros, latinos, pobres, imigrantes), quando, se sentindo sozinha, após cair da escada de sua nobre residência, vê-se amparada pela empregada doméstica M aria, quando então a abraça e a chama de melhor amiga. N o mais "cordial" estilo da dialética "senhorescravo".

X VI. O personagem trágico do iraniano Farhad, interpretado por Snaun Toub, que quer uma arma, sem saber como usá-la ou que munição the seria mais adequada, que desconhece a distinção entre 0 trabalho de um marceneiro e de um chaveiro, assim como desconhece suas obrigações para ter assegurado 0 direito ao pagamento do seguro, representa não um caso de dificuldade de comunicação linguística, mas de absoluta ignorância. A aparente dificuldade de entendimento da língua inglesa, atribuída a Fahrad, é nitidamente um disfarce para a caracterização de um personagem islâmico como paranoico e inconsequente, indigno da cidadania americana ou incapaz de compreender a cultura a ela subjacente. Justificaria os insultos do vendedor da loja de armas, que se nega a vender a arma a Fahrad, vendo-o como epítome de uma ameaça terrorista.

A insensatez do comerciante iraniano, que, armado, vai ao encontro do chaveiro, para assassiná-lo, reputando- o como responsável por toda a sua desgraça, e que por pouco não mata a filhinha do chaveiro $D$ aniel, Lara, parece justificar o vaticínio racista do vendedor de armas estadunidense: imigrantes de origem islâmica, como Fahrad, não merecem, de fato, nenhum dos atributos da cidadania norte-americana. O s EUA seriam melhores se não fossem alguns fanáticos e paranoicos muçulmanos. Pior que isso: a "santa" ignorância dos imigrantes (e a prudente omissão do vendedor americano branco) teria salvado a vida de Lara (e de Daniel), quando a filha de Fahrad, D orri, ao confrontar o vendedor pela injustificável recusa de vender a munição, acaba por adquirir meio que aleatoriamente balas de festim, como se fossem verdadeiras.

É precisamente essa absurda crença (convicta ou inconsciente no delineamento moral dos personagens negros ou islâmicos de C rash), de intrínseca inferioridade de um grupo de pessoas sobre outro, por vezes associada a uma marca visual, física (fenótipo), por vezes vinculada a aspectos simbólicos e culturais, 0 que constitui precisamente 0 racismo, aliás única razão para que esse conceito ainda conserve sua utilidade no plano da análise dos fenômenos sociais (Gui- 
marães, 2005, p. 31), quando há muito - do "A pelo de Atenas", produzido em colóquio da U nesco, em 1981(U nesco, 2007), às conclusões do Projeto Genoma sobre a "invenção das raças" (Barbujani, 2007) - já não se tem dúvida acerca da insubsi stência do conceito do ponto de vista da biologia ou da antropologia física. 0 conceito de raça e de racismo (a que preferimos à novel expressão "racialismo" ) permanece como uma matriz operacional, no campo do direito, da sociologia, da antropologia cultural, da psicologia, exatamente porque, como conceito, sintetiza um certo tipo de subjetividade e de interação social nela baseada que supõe uma pretensamente "natural" inferiorização de um grupo sobre outro. Pouco importa que os argumentos racistas sejam "pseudocientíficos", do ponto de vista biológico, ou que estejam vinculados a marcas de um pretenso "processo civilizatório" diferenciado (Paiva, Sodré, 2004, p. 143).

$R$ eedita-se na ficção um fenômeno muito real e concreto, delineado pelos estudiosos das relações raciais, relacionado a uma roupagem muito mais sutil, simbólica, privatista do racismo contemporâneo do que as formas mais explícitas, públicas, as quais (embora ainda presentes) jamais po deriam gozar de formal aceitação sociojurídica. U m insidioso reforço dos elementos estigmatizadores de um grupo racial ou étnico como "naturalmente" inferior a outro. U ma "oposição assimétrica", ao mesmo tempo cultural, temporal e racial, como teoriza Feres Júnior (2006, p. 172). Em C rash, todos, absolutamente todos os personagens negros do filme são fracos, covardes, submissos, impulsivos, vingativos ou ingratos. Sem exceção. Essa é uma lógica inexorável do filme que, exatamente pela pretensa ilogicidade da trama (casual idades), não pode deixar de conter uma conotação nitidamente racista.

\section{Para além das brancas pipocas - a responsabilidade social e ética da indústria do entretenimento}

Lamentavelmente, essa é a tônica de algumas obras de ficção norte-americanas que trabal ham, de modo mais explícito, com questões raciais, ainda que concebidas por negros. A pretexto de enfrentarem o racismo, terminam por sedimentá-lo de modo ainda mais perverso, posto que sub-reptício. Em D o the right thing (F aça a coisa certa), de 1989, escrito, dirigido, produzido e interpretado por Spike Lee, do qual em muitos aspectos $C$ rash parece ser o complemento ou nele ter se inspirado (o dia mais quente do ano, no primeiro filme, e o dia mais frio do ano, no segundo - são apenas al gumas das vinculações óbvias), os personagens negros são ainda mais estigmatizados como indolentes, arruaceiros, baderneiros, preguiçosos, incivilizados, o que é explicitamente enunciado por eles próprios, quando comparados a um casal de pequenos comerciantes coreanos que se instala na comunidade e que obtém rápido progresso comercial, o que acaba amplificado na medida em que o filme é ambientado num bairro habitado quase que completamente por negros (H udson, 2007, p. 15; A raújo, 2000, p. 78).

Em D o the right thing, "Sal" (Salvatore), interpretado por Danny Ayelo, é um comerciante ítaloamericano, que literalmente "põe a mão na massa" para 0 sucesso de sua pizzaria, instalada há 25 anos no bairro do Brooklyn. Emprega M ookie, jovem negro (interpretado pelo próprio Spike Lee), perdoa seus constantes atrasos e o trata como filho, permitindo até que interfira em assuntos familiares, como o relacionamento conturbado entre Pino e seu irmão, fiIhos de "Sal". M ookie apresenta- se e relaciona- se com Sal e seus filhos como se fossem integrantes de uma mesma família e não como empregados e patrões. $E$ tal como o pai de R yan, em C rash, Salvatore, em D o the right thing, tendo sido sempre um "simpatizante" da comunidade negra, acaba sendo por ela arruinado. Se a ruína pessoal do pai de $\mathrm{R}$ yan, em $\mathrm{C}$ rash, teria decorrido dos contratos da prefeitura, que passou a implementar políticas afirmativas, Sal, em D o the right thing, tem sua pizzaria destruída pelos vizinhos negros, revoltados com a morte do personagem $\mathrm{R}$ adio $\mathrm{R}$ aheem (Bill N unn), ao ser detido por policiais que procuravam conter a briga na pizzaria, provocada por $\mathrm{R}$ adio $\mathrm{R}$ aheem e Buggin $\mathrm{O}$ ut (Giancarlo Esposito).

0 filho de Sal, Pino, que explicita em diversas passagens sua aversão pelos negros (embora fã de alguns negros "diferentes", como Eddie Murphie, $M$ agic Johnson, Barry Manilow, Prince), vaticina ao irmão uma profecia: "você será apunhalado pelos negros à primeira vez que Ihes der as costas, pois nenhum negro é confiável". I sso após tentar convencer o pai, sem sucesso, a transferir sua pizzaria para outro local, enquanto ainda estivessem vivos. E a profecia se autorrealiza quando, terminada a briga na pizzaria, 0 próprio M ookie, o negro protegido de Sal (e tratado como se fosse seu filho e futuro herdeiro), é o primeiro a arrebatar um latão de lixo e arremessar contra a janela da pizzaria, incitando seus demais "irmãos de cor" a fazer o mesmo, até destruírem completamente o estabelecimento.

No dia seguinte ainda interpela Sal, o dono da pizzaria, para que pague o que Ihe deve, reivindicação que acaba sendo aceita por Sal, apesar dos prejuízos com a destruição do estabelecimento (iniciada por M ookie). Sal tira do bolso U S\$500 e joga o dinheiro em direção a M ookie, que recolhe cada cédula caída no chão. Com efeito, a reivindicação do pagamento, por Mookie (em meio ao que restou da pizzaria de Sal), dificulta eventual interpretação de que ele atirou a lata de lixo, incitando os demais a destruírem a 
pizzaria, por simples indignação pela morte de $\mathrm{R}$ adio $\mathrm{R}$ aheemn (a denotar que a vida sempre haveria de ter um valor maior que o patrimônio). Se assim o fosse, certamente não teria feito tanta questão de exigir o pagamento (pela destruição por ele próprio iniciada), em meio ao seu infortúnio pessoal. A cena de M ookie abaixando-se para recolher as cédulas, em meio à desgraça de Sal, fala por si. 0 curioso é constatar que essa cena foi idealizada, dirigida e interpretada pelo insuspeito Spike Lee, num inusitado "ato falho".

$\mathrm{Em} \mathrm{C}$ rash, o racismo de $\mathrm{R}$ yan é obtemperado pelo comportamento indecente (de C hristine e C ameron), vingativo, injusto, ingrato (de Shaniqua Johnson) ou criminoso (osladrões A nthony e Peter), de quem simplesmente se recusa a trabalhar duro, tomar ônibus, fazer serviços subalternos. Em D o the right thing, o racismo de Pino é também neutralizado pela ingratidão e intolerância de M ookie (e toda a comunidade negra do bairro) a Salvatore, o bonachão dono da pizzaria, até então orgulhoso de alimentar gerações de vizinhos negros, encantado com a beleza da jovem Jade, irmã de M ookie.

É como se no fundo R yan (de C rash) e Pino (de $D 0$ the right thing) não fossem racistas (parece ser esta uma representação simbólica e ideológica comum a ambos os filmes), mas simplesmente não tolerassem negros vagabundos, desordeiros, indolentes, incivilizados, os quais se recusam a arcar com o ônus (do trabalho duro, da dedicação, do estudo, da disciplina) que alimenta o progresso individual, conquanto reivindiquem direitos de igualdade (Feres Junior, 2006, p. 172). C omo se os próprios negros fossem responsáveis pela discriminação que recebem, que seria muito mais decorrente de uma postura individual diante da vida (reivindicassem menos e trabalhassem mais, seriam mais felizes) e não por razões históricas, políticas e socioeconômicas.

$\mathrm{N}$ essas obras de ficção, a postura indolente diante da vida (que evidentemente pode ser reconhecida em qualquer grupo étnico) é sempre estigmatizada como pertencente aos negros (até os latinos ou orientais, nesse aspecto, são poupados - vide as imagens positivas de trabalhadores atreladas a $\mathrm{R}$ ia, $\mathrm{D}$ aniel e D orri em $C$ rash, e do casal coreano em $\mathrm{D} 0$ the right thing). Como se o racismo, o preconceito, a discriminação racial não fossem invenção dos brancos, mas dos próprios negros, cujos comportamentos sociais estariam sempre a justificar que, em verdade, não estão ainda em condições de compreender e de se amoldar às regras do mundo civilizatório branco e ocidental. U m racismo ancorado numa ideologia (no sentido que the dá C hauí, 2001, p. 108), reinventado e justificado pe- los próprios negros. Como se "gratuitamente" ou por livre e espontânea vontade, preenchessem em número tão expressivo as vagas dos presídios, dos necrotérios, dos subempregos, dos hospitais psiquiátricos (como criticamente menciona a pungente letra de uma canção popular brasileira $\left.{ }^{3}\right)$. A mbos os filmes carreiam a sub-reptícia mensagem da irracionalidade, da passividade, da submissão, do inato desajuste (inadaptação social), da incivilidade dos grupos estigmatizados, 0 que constitui uma expressão mais sutil (e não menos perversa) de preconceito racial, uma espécie de "racismo de atitudes" (cf. Guimarães, 1999, p. 107).

$C$ rash ou $D O$ the right thing encaixam-se naquilo que rotulamos de "antirracismo racista". E aí Hollywood, ao se pretender séria, engajada, ao tocar temas além do simples e puro entretenimento, acaba colocando mais um tijolo simbólico na longa e paulatina construção e no reforço estrutural de estereótipos acerca dos negros, alimentando o racismo e pouco contribuindo para suprimir o preconceito e a discriminação racial. Por isso, recebemos com surpresa 0 fato de o filme $C$ rash ter sido ganhador (além de uma dezena de outros prêmios) do H umanitas Prize, prêmio de excelência na escrita cinematográfica e televisiva, dedicado a louvar "histórias que afirmam a dignidade da pessoa humana, investigam o significado da vida, e iluminam o exercício da liberdade humana; a histórias que velam pela humanidade comum, para que 0 amor possa permear a família humana e auxiliar a liberar, enriquecer e unificar a sociedade". ${ }^{4}$ I gualmente surpreendentes os inúmeros prêmios, coletivos ou individuais, relacionados ao filme, conferidos pelo Black M ovie Awards. Surpresa porque, por trás das explícitas cenas de ódio, preconceito, racismo, que evidentemente chocam e escandalizam o espectador (e que, evidentemente, o filme procura repudiar, denunciando-as de forma brutal), esconde-se (consciente ou inconscientemente) uma mensagem moral muito incisiva e penetrante (posto que sub-reptícia) na linha diametralmente oposta àquela (socialmente responsável) que os autores da história apregoam: "0 que seria dos negros se não fossem os brancos?" ou (o que é a mesma coisa): "como o mundo dos brancos seria melhor não fossem os negros".

Convém frisar que não estamos aqui a patrulhar uma obra de ficção, exigindo que siga o caminho do bom samaritano, execrando, de forma explícita, unilateral ou "romântica" os "males do racismo", sem deixar qualquer mensagem ambígua acerca do posicionamento de seus criadores ou de seus personagens. A indústria do entretenimento seria mesmo muito enfadonha se tivéssemos de ler todos as obras de ficção

3 Primeira estrofe da canção "A carne", de Seu Jorge, Marcelo Yuca e Ulisses Cappelletti, imortalizada na voz da cantora Elza Soares: "A carne mais barata do mercado/É a carne negra/ Que vai de graça pro presídio/E para debaixo do plástico/E vai de graça pro subemprego/E pros hospitais psiquiátricos."

4 Tradução livre do significado do prêmio, consoante registrado em sua própria página eletrônica (www.humanitasprize.org.br). 
como documentários ou papers acadêmicos. 0 corre que quando uma obra de ficção se propõe a abordar, de forma direta e convicta, temas sociais, jurídicos ou políticos, abre-se necessariamente ao escrutínio universal de sua tessitura discursiva, quer queiram ou não seus criadores. As artes em geral e a mídia televisiva e cinemática, em especial (diante de seu extenso, instantâneo e global efeito difusor), não podem se eximir de sua responsabilidade social, ética e política. Principalmente quando seus criadores optam por trabalhar com temas e enfoques especialmente complexos - no plano das razões e das sensibilidades - como é a questão racial, ainda mais entrecortada por vetores de gênero, classe, igualdade e justiça. Se, quando o fazem, acabam por sutilmente reforçar estereótipos históri$\cos$, culturais e sociais, tão deletérios à luta secular e universal de erradicação do racismo, do preconceito, do ódio, da discriminação, devem reconhecer o contraposto direito de observadores externos (evidentemente, com as armas do rigor analítico, com fundamentação o menos passional possível) de apresentarem visões alternativas, críticas ou mesmo opostas à ideologia a que tais obras procuram se apoiar ou referendar, consciente ou inconscientemente.

Como assentado no Brasil, pelo Supremo Tribunal Federal, no caso Ellwanger, ${ }^{5}$ exigir do trabalho intelectual (profissional, artístico, científico ou de entretenimento) responsabilidades éticas e conformidade com os ditames de nossas leis, constituições e tratados internacionais não significa suprimir ou reduzir a liberdade de expressão, mas de harmonizá-la com princípios e valores caros, como a igualdade e a dignidade da pessoa humana. ${ }^{6} \mathrm{Com}$ efeito, as polêmicas obras de Ellwanger (que se propunham a refutar o Holocausto judeu, fazendo apologia de ideias preconceituosas, racistas e discriminatórias) ao menos não renegam seus objetivos explícitos. Talvez até mais perigosas e deletérias sejam as sub-reptícias, insidiosas formas de racismo em meio a trabalhos desde o início orientados a expor uma tese contrária ao racismo.

\section{The end ou "até quando?" - à guisa de conclusão}

C rash é mais que uma pancada, uma colisão, um soco na boca do estômago de todos os que sinceramente acreditam no ideal de solidariedade e de fraterna convivência entre os vários grupos raciais ou étni- cos. Pressupõe irremediável um conflito entre, de um lado, os cidadãos estadunidenses, brancos e ocidentais (sintetizados na formula "Wasp" - white anglo-saxon puritan), e, de outro lado, cidadãos negros, latinos e orientais. A presenta elementos de uma rica, reiterada e consistente imagística (demonstrada anteriormente), de coerência absolutamente incoerente com a aparente incoerência e casualidade da trama, no sentido de um inevitável aniquilamento moral de um grupo sobre o outro, embora aparentemente a isso pretenda se opor.

O s esbarrões, os encontrões físicos, os conflitos, os choques, as incompreensões que o filme retrata na interação dos personagens não deixam esconder, qual ato falho, uma visão profundamente centrada (ou inconscientemente arraigada) da natural superioridade de um grupo étnico sobre o outro. 0 s embates e conflitos raciais, retratados no filme, permeiam uma atitude ambígua, de atração e repulsa ao próprio racismo, com suas explosivas combinações com as dimensões de gênero, classe, igualdade e justiça.

Q uem sabe precisemos mais de filmes em que a temática racial, em meio às interações sociais, políticas, econômicas e amorosas entre os personagens, não se apresentem como "temática racial", mas exatamente para propor sua superação retratem de tal forma 0 inter-relacionamento entre negros e brancos como algo indigno de chamar atenção. E que o delineamento moral dos personagens não seja tão abusivamente seletivo, discriminatório. Se com D urkheim aprendemos que o crime há de ser considerado um fato social "normal", ainda que de consequências indesejáveis, a legitimar uma resposta penal do Estado (como censura ou como sanção), que então esteja relacionado, também na ficção, como um fato associado a pessoais "normais", brancas e negras, altas e baixas, gordas e magras, ricos e pobres, latinos ou orientais. O xalá vivenciemos o dia em que não precisemos acrescentar marcas fenotípicas adjetivando profissões, papéis e funções sociais (o prefeito negro, o jogador negro, 0 astronauta negro, o músico negro, o cientista negro, 0 artista negro, 0 assaltante negro), se é certo que tais adjetivações nunca se fazem presentes em relação aos brancos.

0 alerta que esperamos promover nesta análise de $C$ rash (e aproveitamos aqui para render nossas sinceras homenagens aos organizadores desta coletânea de ensaios) é de que, embora não se trate de um documentário (cuja "verdade dos fatos" possa ser facilmente contraposta) ou de um artigo acadêmico (cuja "verdade das ideias" pode ser igualmente refutada), a estrutura simbólica e ideológica de seu roteiro encerra

5 HC 82424-2, Pleno do Supremo Tribunal Federal, relator ministro Maurício Correa, julgado em 17/09/03, publicado no DJ de 19/04/2004, p. 17.

6 "As liberdades públicas não são incondicionais, por isso devem ser exercidas de maneira harmônica, observados os limites definidos na própria Constituição Federal (CF, artigo $5^{\circ}, \S 2^{\circ}$, primeira parte). O preceito fundamental de liberdade de expressão não consagra o 'direito à incitação do racismo', dado que um direito individual não pode constituir-se em salvaguarda de condutas ilícitas, como sucede com os delitos contra a honra. Prevalência dos princípios da dignidade da pessoa humana e da igualdade jurídica" (precedente do STF já citado). 
elementos analíticos em torno da questão racial que nos permite concluir ser manifestamente falsa e enganadora a "lógica" ou " justificativa" de sua trama como sendo uma crua retratação do racismo, para que nos envergonhemos de sua existência. A forma como os personagens brancos e negros se entrelaçam, se esbarram, trombam e caem, em suas falas, atos e concepções morais, deixa muito bem impressa a mensagem de uma pretensa superioridade branca (Paiva; Sodré, p. 143). Como se o mundo pudesse ser menos problemático, menos conflituoso, mais pacífico, não fossem os negros. Talvez estes representem as perturbadoras "pequenas nuvens negras que permanecem pairando ao redor" (de que nos fala a letra da música-tema do filme, "M aybe tomorrow"), impedindo os brancos e ricos de chegarem, sem sobressaltos ou conflitos de consciência, ao encontro de seus lares. ${ }^{7}$
Talvez no futuro (maybe tomorrow), sem se perder ou retroceder, o tema das relações raciais, na cinematografia hollywoodiana, possa vir emoldurado por histórias ficcionais que sinceramente acreditem na diferença e na diversidade como parceiras (e não obstáculos) à democracia, ao Estado de direito, à justiça, ao desenvolvimento humano. Q ue não abusem, consciente e inconscientemente, de símbolos, valores, crenças e estereótipos que hierarquizem raças ou culturas (expressão maior do racismo), justificando e perpetuando, de forma tão perversa, a discriminação, 0 ódio, a intolerância (A raújo, 2000, p. 77). Q ue não substituam a violência real pela violência simbólica, centrada numa ideologia desagregadora. E que qualquer semelhança (no delineamento moral dos personagens de uma história) com os estereótipos racistas da vida real possa ser de fato mera coincidência.

7 Primeira estrofe da canção "Maybe tomorrow", escrita por Kelly Jones, Richard Mark Jones e Stuart Cable, interpretada pela banda galesa Stereophonics: "I've been down and/I'm wondering why/These little black clouds/Keep walking around with me/With me... So maybe tomorrow/l'll find my way home."

\section{Referências}

AR AÚ J0, Joel Zito. Identidade racial e estereótipos sobre o negro na TV brasileira. In: GU IM AR Ã ES, A ntonio Sérgio; H U N T LEY, Lynn. T irando a máscara: ensaios sobre o racismo no Brasil. São Paulo: Paz e Terra, 2000.

BAR BUJANI, Guido. A invenção das raças. São Paulo: Contexto, 2007.

CH AU Í, M arilena. 0 que é ideologia. 2. ed. São Paulo: Brasiliense, 2001.

DIKEN, Bülent; LAU ST SEN, C arsten. B eing abject: rape as a weapon of war. B ody and Society, 11, n. 11, 2005, p. 111-128.

FER ES JÚ N IOR , João. A spectos semânticos da discriminação racial no Brasil - para além da teoria da modernidade. R evista B rasileira de C iências Sociais, São Paulo, 21 (61), jun. 2006, p. 164-176.

GU IM AR ÃES, A ntonio Sérgio. Combatendo o racismo: Brasil, Á frica do Sul e Estados U nidos. R evista B rasileira de C iências Sociais, 14, n. 39, jan. 99, p. 107.

.R adismo e anti- racismo no B rasil. 2 ed. São Paulo: Editora 34, 2005.

H U DSO N, Barbara. Direitos humanos e "novo constitucionalismo": princípios de justiça para sociedade divididas. In: CLÉVE, Clèmerson; SAR LET, Ingo Wolfgang; PAGLIAR IN I, A lexandre C outinho(O rgs.). D ireitos humanos e democradia. R io de Janeiro: Forense, 2007

IA N N I, O ctavio. Dialética das relações raciais. Estudos A vançados, São Paulo, 18, n. 50, 2004, p. 21-30.

LI M A, M arcus Eugênio O liveira; VA LA, Jorge. As novas formas de expressão do preconceito e do racismo. Estudos de Psicologia, N atal, 9, n. 3, 2004, p. 401-411.

MILILLO, Diana. R ape as a tactic of war - social and psychological perspectives. A ffilia, vol. 21, n. 2, 2006, p. 196-205.

PAIVA, R aquel; SO DR É, M uniz. M ídia, comunidade e preconceito racial. Sphera Publica, M urcia (Espanha), n. 4, 2004, p. 141-149.

R A M OS, Silvia; M U SU M ECI, Leonarda. Elemento suspeito: abordagem policial e discriminação na cidade do $\mathrm{R}$ io de Janeiro. R io de Janeiro: Civilização Brasileira, 2005.

R EIN ER, R obert. T he politics of the police. Londres: $\mathrm{H}$ arvester $W$ heatsheaf, 1992.

R O SO, Adriane; ST R EY, M arlene N eves; GUAR ESC HI, Pedrinho; BU EN O, Sandra M . N ora. Cultura e ideologia: a mídia revelando estereóti pos raciais de gênero. Psicologia e Sociedade, v. 14, n. 2, jul.dez. 2002, p. 74-94.

U N ESC O . A pelo de A tenas - A voz da ciência contra o racismo. Disponível em: <w w w.unesdoc.unesco.org>. Acesso em: 10. 08. 2007. 


\title{
Race, gender, class, equality and justice: symbolic and ideologic representations of Paul Haggis' film Crash
}

\begin{abstract}
This study examines the film $\mathrm{C}$ rash, by Paul $\mathrm{H}$ aggis, from the perspective of race relations studies. It analyzes the symbolic and ideological content of the metalanguage of $\mathrm{C}$ rash (the way the story is told) rather than the openly racist language of the film's characters (the explicit content of the story that istold). Through a very accurate comparison of the fictional and discursive framework of the film with historical and contemporary analytical contexts in the field of race relations (and their relationship with issues of gender, class, equality and justice), the essay shows how a surreptitious racist ideology is allowed to permeate $C$ rash (particularly in the form of the stereotyped and stigmatizing moral shape given to the black characters compared with the white ones) under the protective mantle of a film that apparently aims to fight racism. This essay argues that $C$ rash is a typical example, both in terms of fiction and reality, of what it calls "racist anti-racism". In the end, the essay points out the need for social and ethical responsibility in the entertainment industry and their compatibility with freedom for artistic creativity.
\end{abstract}

Key words: racism; anti-racism; gender; class; entertainment industry

\section{Raza, género, clase, igualdad y justicia: representaciones simbólicas $e$ ideológicas de la película Crash, de Paul Haggis}

\begin{abstract}
Resumen
Este ensayo examina la película $\mathrm{C}$ rash, de Paul $\mathrm{H}$ aggis, bajo la óptica de los estudios sobre las relaciones raciales. Emprende una lectura del simbólico e ideológico del metalenguaje de C rash (la forma como la historia es contada) y no del lenguaje ciertamente racista de sus personajes - el contenido explícito de la historia contada. Cotejando, con fidelidad, la moldura ficcional y discursiva de la película con los horizontes analíticos históricos y contemporáneos en el tema de las relaciones raciales -y sus correlaciones con las cuestiones de género, clase, igualdad y justicia-, el ensayo identifica el modo como Crash permite incorporar una subrepticia ideología racista - particularmente en el estereotipado y estigmatizante delineamiento moral de los personajes negros, comparativamente a los personajes blancos-, bajo el manto de protección de una película que aparentemente propone combatir el racismo. C rash sería, en el argumento del ensayo, un típico ejemplo - de ficción y de realidad- del que se denomina por "antirracismo racista". Al final, el ensayo Ilama la atención para la responsabilidad social y ética de la industria del entretenimiento y su compatibilidad con la libertad de creación artística.
\end{abstract}

Palabras-clave: racismo; antirracismo; género; clase; industria del entretenimiento 
324 Sociedade e Cultura, v.12, N.1, Jan/Jul. 2009 